\title{
Long acting porcine sequence ACTH in the diagnosis of adrenal insufficiency
}

\section{Abilash Nair ${ }^{1}$, Chellamma Jayakumari', Geena Susan George', Puthiyaveettil Khadar Jabbar', Darvin V Das', S J Jessy² and T S Aneesh ${ }^{3}$}

Departments of ${ }^{1}$ Endocrinology and Metabolism, ${ }^{2}$ Biochemistry, and ${ }^{3}$ Community Medicine, Government Medical College, Thiruvananthapuram, India
Correspondence should be addressed to A Nair or C Jayakumari Email abhimck@gmail.com or drcjayakumarimch@gmail. com

\begin{abstract}
Objectives: Injectable tetracosactide hexa-acetate, ACTH 1-24 (Synacthen), is not marketed in many countries including India, whereas Injectable long acting porcine sequence, ACTH 1-39 (Acton Prolongatum ${ }^{\circledR}$ ) is easily available and much cheaper. This study aimed to find the diagnostic accuracy of ACTH stimulation test using i.m. Acton Prolongatum ${ }^{\circledR}$ (acton prolongatum stimulation test, APST) in comparison with Synacthen (short synacthen test, SST) for the diagnosis of glucocorticoid insufficiency.

Methods: Subjects with a suspicion of adrenal insufficiency based on clinical features underwent a SST with $250 \mu \mathrm{g}$ Synacthen followed by APST using 30 units of Acton Prolongatum ${ }^{\circledR}$. Serum cortisol levels were measured at 60 and 120 min following injection of Acton Prolongatum ${ }^{\circledR}$. Stimulated peak cortisol of less than $18 \mu \mathrm{g} / \mathrm{dL}$ on SST was considered as adrenal insufficiency.

Results: Forty seven patients with mean age of $36.7 \pm 14.4$ years were enrolled for the study. Based on SST, twenty $(n=20)$ persons were classified as having adrenal insufficiency, whereas twenty-seven $(n=27)$ were found to be normal. Area under the curve of APST (at $120 \mathrm{~min}$ ) was 0.986 when compared to SST, thus proving its high accuracy. A serum cortisol cut off value of $19.5 \mu \mathrm{g} / \mathrm{dL}$ at 120 -min following stimulation with Acton Prolongatum ${ }^{\circledR}$ showed a sensitivity of $100 \%$ and specificity of $88 \%$.

Conclusion: ACTH stimulation test using Acton Prolongatum ${ }^{\circledR}$ is an economical and accurate alternative to the short Synacthen test.
\end{abstract}

\section{Introduction}

Early diagnosis of adrenal insufficiency (AI) can be lifesaving (1). Morning cortisol level is useful for the detection of adrenal insufficiency in cases where it is markedly low or clearly in the upper reference range $(2,3)$. Still, in a majority of patients, stimulation tests are required for the definitive diagnosis of AI. Although the reference test for the diagnosis of AI is measurement of cortisol response to insulin-induced hypoglycemia, it is contraindicated in patients with ischemic heart disease and epilepsy and may be risky in patients with primary AI. Current guidelines suggest the use of standard dose $(250 \mu \mathrm{g})$ Short Synacthen Test (SST) for the diagnosis of both primary (4) and secondary AI (5). Synacthen or Cosyntropin (tetracosactide hexaacetate) is a synthetic adrenocorticotropic hormone (ACTH) composed of the first twenty-four amino acids of the ACTH 1-39 peptide. Synacthen is not marketed in India; hence, the cost is prohibitively high. Constraints of procurement have led to avoidance of ACTH stimulation test even when indicated, with undue reliance on morning cortisol values. Synthetic porcine sequence corticotrophin in carboxymethylcellulose is freely available as Acton Prolongatum $^{\circledR}$ in a $5 \mathrm{~mL}$ multidose vial manufactured by Ferring's Pharma. When used at a dose of 30 IU per test it costs 14 times less than $250 \mu \mathrm{g}$ of Synacthen. Reversible

Published by Bioscientifica Ltd. 
binding of ACTH to carboxymethyl cellulose protects the peptide against enzymatic breakdown thereby prolonging its action. Acton Prolongatum is preserved at $2-10^{\circ} \mathrm{C}$ and administered intramuscularly (6).

Although Acton Prolongatum stimulation test (APST) is used in many centers in India for diagnosing AI, there is paucity of literature to strongly support this practice. This study was done to evaluate the performance of APST and validate it against the standard SST.

\section{Subjects and methods}

The study was conducted in a prospective observational design, in the Department of Endocrinology, Government Medical College Hospital, Thiruvananthapuram, India. The study was approved by the Human Ethics Committee of Govt. Medical College Thiruvananthapuram and funded by the State Board of Medical Research, Kerala. All patients with clinical suspicion of AI (anorexia, nausea, weight loss, unexplained hyponatremia, progressive hyperpigmentation, history of pituitary macroadenoma or surgery) who attended the outpatient clinic during the study period were included. Written, informed consent was obtained from all the subjects after explaining the procedure. Demographic details and symptomatology of each individual were entered into a pre-designed proforma.

Baseline serum cortisol was measured at between 8:00 $\mathrm{h}$ and 9:00 $\mathrm{h}$ in all subjects. Short Synacthen Test (SST) was carried out by administering $250 \mu \mathrm{g}$ of Synacthen intramuscularly to deltoid followed by venous blood sampling for serum cortisol at 30 (SST 30) and 60 (SST 60) min. Three days later APST was performed by injecting $0.5 \mathrm{~mL}$ (30 units) of Acton Prolongatum ${ }^{\circledR}$ intramuscularly to deltoid followed by venous blood sampling for serum cortisol at 60 (APST 60) and 120 (APST 120) min. A dose of 30 units was chosen to ensure ease of dispensing $(0.5 \mathrm{~mL})$ from a 300 unit in $5 \mathrm{~mL}$ formulation. Stimulated peak cortisol cut off of less than $18 \mu \mathrm{g} / \mathrm{dL}$ on SST was considered as AI based on guideline recommendations (4). Patients were closely monitored for any discomfort or adverse events. Delta cortisol was calculated as the maximum increment in serum cortisol following the administration of Acton Prolongatum ${ }^{\circledR}$. Serum cortisol estimation was done by electrochemiluminescence method using COBAS e 411 analyzer with Cortisol II kits, which has an intraand inter-assay coefficient of variation of $1.6-2.4 \%$ and measuring range of $0.054-63 \mu \mathrm{g} / \mathrm{dL}$.

Data was tabulated using Microsoft excel and analyzed using SPSS, version 25. Continuous variables were described using mean and S.D. and categorical variables as frequency and percentages. Receiveroperating characteristic (ROC) curve was plotted using a uniform threshold for any selected variables according to $95 \%$ specificity. Area under the curve (AUC) was used to express the overall diagnostic accuracy of the index criterion. $P$ value was considered to be significant at $5 \%$ level of significance for all comparisons. Youden index was used to find out the cut off levels at which the best possible sensitivity and specificity was obtained.

\section{Results}

During the study period, 54 patients with clinically suspected AI were encountered in the outpatient clinic, of whom four were excluded due to liver disease. Thus, 50 persons were included to undergo the SST and APST. The SST was done in 50 patients, of whom three patients did not turn up for the second test and were considered as having withdrawn consent. The remaining 47 patients were included in the final analysis (Fig. 1). The mean age of the study population was $36.7( \pm 14.46)$ years. There were 26 (55.3\%) female patients and 21 (44.6\%) male patients. The mean BMI of the study group was $25.3 \pm 5.2$ $\mathrm{kg} / \mathrm{m}^{2}$. None of the patients experienced any immediate adverse events like nausea, vomiting, rash or anaphylaxis with Synacthen or Acton Prolongatum ${ }^{\circledR}$.

Of the 47 patients with suspected AI, 20 (42.5\%) were confirmed to have AI based on the SST using a stimulated peak cortisol cut off of less than $18 \mu \mathrm{g} / \mathrm{dL}$. Of these, four patients had primary AI and the remaining had secondary AI based on clinical features and ACTH levels.

If $14.5 \mu \mathrm{g} / \mathrm{dL}$ is taken as the cut off for diagnosis of adrenal insufficiency on a SST, as suggested by recent studies which had used the same equipment and kits (Roche COBAS e 411 and Cortisol II), only 16 patients would be classified as having the disease $(7,8,9)$.

\section{Performance of APST in subjects with normal adrenal reserve}

Among the patients without AI based on SST, the mean basal serum cortisol levels were $7.2( \pm 1.8) \mu \mathrm{g} / \mathrm{dL}$ and the values at 30 and $60 \mathrm{~min}$ were $20.8( \pm 3.2) \mu \mathrm{g} / \mathrm{dL}$ and 20.3 $( \pm 4.0) \mu \mathrm{g} / \mathrm{dL}$ respectively after Synacthen administration. The mean serum cortisol values with APST were $22.6( \pm 5.1)$ and $26.1( \pm 5.5) \mu \mathrm{g} / \mathrm{dL}$ at 60 and $120 \mathrm{~min}$, respectively. The mean serum cortisol values at $1 \mathrm{~h}$ after stimulation with Acton Prolongatum ${ }^{\circledR}$ were numerically higher 


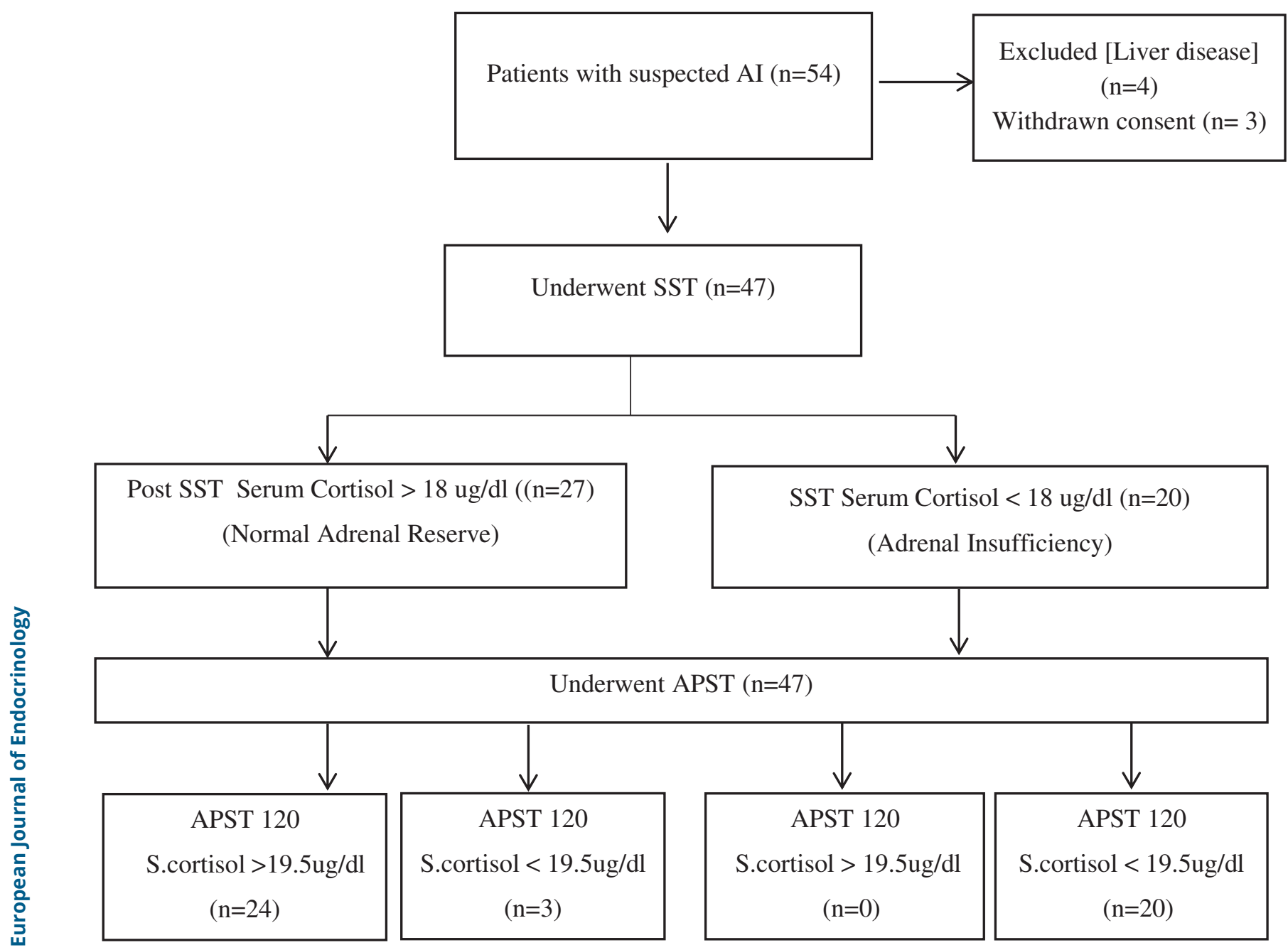

\section{Figure 1}

Flow of the study.

by approximately $2.3 \mu \mathrm{g} / \mathrm{dL}$ when compared to that after Synacthen, but the difference was not statistically significant (Table 1) $(P=0.072 ; 95 \% \mathrm{CI},-4.65$ to 0.21$)$.

\section{Performance of APST in subjects with Al}

Among the patients with AI, the mean basal serum cortisol levels were $4.5 \pm 3.5 \mu \mathrm{g} / \mathrm{dL}$. During the SST the cortisol levels had a rise to a mean of $7.9( \pm 5.1) \mu \mathrm{g} / \mathrm{dL}$ at $30 \mathrm{~min}$ and 9.3 $( \pm 6.2) \mu \mathrm{g} / \mathrm{dL}$ at $60 \mathrm{~min}$. The mean serum cortisol values with APST were $9.8( \pm 6.0) \mu \mathrm{g} / \mathrm{dL}$ at $60 \mathrm{~min}$ and $10.6( \pm 6.4)$ $\mu \mathrm{g} / \mathrm{dL}$ at $120 \mathrm{~min}$ respectively. S. cortisol values at $1 \mathrm{~h}$ after stimulation with Synacthen and Acton Prolongatum ${ }^{\circledR}$ were similar $(P=0.796 ; 95 \% \mathrm{CI}-4.44$ to 3.42$)$ (Table 1$)$.

\section{Receiver-operating characteristic}

Receiver-operating characteristic (ROC) analysis was performed for the basal as well as post APST serum cortisol levels (at 60 and $120 \mathrm{~min}$ ) and area under the curve (AUC)

Table 1 Comparison of cortisol values at different time points during APST and SST in patients with and without AI.

\begin{tabular}{|c|c|c|}
\hline \multirow[b]{2}{*}{ Time (min) } & \multicolumn{2}{|c|}{ Patients without Al } \\
\hline & SST cortisol ( $\mu \mathrm{g} / \mathrm{dL})$ & APST cortisol ( $\mu \mathrm{g} / \mathrm{dL})$ \\
\hline 0 & $7.3 \pm 1.9$ & $7.3 \pm 1.9$ \\
\hline 30 & $20.9 \pm 3.2$ & NA \\
\hline 60 & $20.3 \pm 4.1$ & $22.6 \pm 5.2$ \\
\hline 120 & NA & $26.1 \pm 5.6$ \\
\hline
\end{tabular}

\begin{tabular}{|c|c|}
\hline \multicolumn{2}{|c|}{ Patients with Al } \\
\hline SST cortisol ( $\mu \mathrm{g} / \mathrm{dL})$ & APST cortisol $(\mu \mathrm{g} / \mathrm{dL})$ \\
\hline $4.6 \pm 3.5$ & $4.6 \pm 3.5$ \\
\hline $7.8 \pm 5.0$ & NA \\
\hline $9.3 \pm 6.2$ & $9.8 \pm 6.1$ \\
\hline NA & $10.6 \pm 6.37$ \\
\hline
\end{tabular}




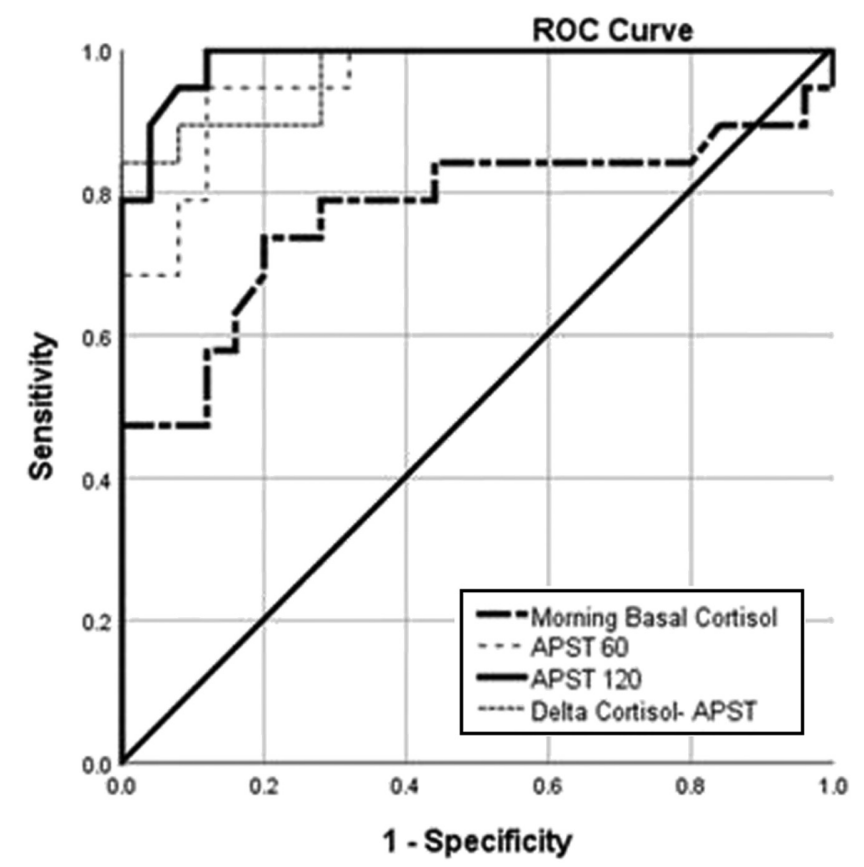

Figure 2

Receiver-operator characteristic (ROC) curve plot analysis for morning basal cortisol, APST 60, APST 120 and delta cortisol. The maximum area under ROC was for APST 120 (0.986).

was found out for basal cortisol, APST 60 min, APST 120 min, peak APST cortisol value, mean of post APST cortisol values and Delta cortisol (difference between basal and peak cortisol). Acton Prolongatum ${ }^{\circledR}$ stimulated serum cortisol at 120 min (APST 120) showed maximum area under the curve among the analyzed parameters (Fig. 2 and Table 2) A diagnostic cut off of $19.5 \mu \mathrm{g} / \mathrm{dL}$ provided the highest sensitivity and specificity both for APST 120 (100 and $88 \%$ respectively) and peak cortisol after APST (95 and $89 \%$ ). For the proposed lower (assay specific) SST cut off of $14.5 \mu \mathrm{g} / \mathrm{dL}$ the corresponding cut-off for APST was found to be $18.6 \mu \mathrm{g} / \mathrm{dL}$ both for APST 120 (sensitivity 100\% and specificity 84\%) and peak cortisol after APST (sensitivity $94 \%$ and specificity $84 \%$ ) based on ROC analysis.

\section{Performance of morning cortisol}

Morning cortisol values in patients with $\mathrm{AI}$ and those without AI were $7.3 \pm 1.9 \mu \mathrm{g} / \mathrm{dL}$ and $4.6 \pm 3.5 \mu \mathrm{g} / \mathrm{dL}$ respectively. Although there was a considerable overlap between these values, a morning cortisol level below 3.6 $\mu \mathrm{g} / \mathrm{dL}$ provided $100 \%$ specificity for diagnosing AI (Table 2). If this value of morning cortisol is taken as a cut off for diagnosis of AI, ACTH stimulation test could have been avoided in 9 (19.1\%) out of the 47 patients.

\section{Primary versus secondary Al}

Patients with AI were classified as having primary or secondary AI on the basis of clinical features and plasma ACTH levels. Of the 20 patients with AI, 16 had secondary AI and 4 had primary AI. Mean age of patients with primary and secondary AI was 44.5 (19-64) years and 38 (17-80) years and mean BMI was $24.0 \mathrm{~kg} / \mathrm{m}^{2}$ vs $26.2 \mathrm{~kg} / \mathrm{m}^{2}$ respectively. Autoimmune adrenalitis and tuberculosis were the probable cause in patients with primary AI. Pituitary surgery, pituitary macroadenoma, stalk interruption syndrome and prior long-term steroid exposure were the etiologies in secondary AI. The mean basal cortisol values were $2.2( \pm 2.9)$ and $4.8( \pm 2.9)$ in primary and secondary AI respectively $(P=0.135)$. Patients with primary AI achieved a much lower mean peak cortisol level $2.1( \pm 2.4) \mu \mathrm{g} / \mathrm{dL}$ after APST compared to those with secondary AI who had a mean peak cortisol level of $12.7( \pm 5.1) \mu \mathrm{g} / \mathrm{dL}$.

\section{Discussion}

SST is the current standard of care for the diagnosis of AI. Unavailablility of Synacthen in large parts of the world makes the diagnosis of AI fraught with challenges of under diagnosis as well as over diagnosis. Synthetic porcine sequence corticotrophin (Acton Prolongatum ${ }^{\circledR}$ ) is readily available, stable and cheaper than Synacthen. Present study was done to assess the performance of APST against SST.

Animal studies comparing porcine ACTH in gelatin (1-39 amino acid sequence) and synthetic ACTH (1-24 amino acid sequence) in female dogs revealed no significant difference and concluded that either method caused maximal secretion of the adrenocortical reserve when administered in equimolar amounts (10). Friedman et al. studied 11-hydroxycorticosteroid levels following long acting corticotrophin carboxymethyl cellulose and found peak cortisol levels around 1 to $3 \mathrm{~h}(25.7 \mu \mathrm{g} / \mathrm{dL}$ at 1 $\mathrm{h}$ and $37.4 \mu \mathrm{g} / \mathrm{dL}$ at $3 \mathrm{~h}$ ) (11). Hence, in the present study, serum cortisol values up to $2 \mathrm{~h}$ following administration of Acton Prolongatum ${ }^{\circledR}$ were measured. All patients underwent SST followed by APST, where SST was used to classify the patients to be glucocorticoid sufficient or insufficient, and results of APST were compared. It was demonstrated that APST can be safely and reliably utilized for the diagnosis of glucocorticoid insufficiency with a high sensitivity (100\%) and specificity (88\%). The best cut off for stimulated cortisol after Acton Prolongatum ${ }^{\circledR}$ administration was determined to be $19.5 \mu \mathrm{g} / \mathrm{dL}$ 
Table 2 Comparison of performance among various parameters obtained from APST.

\begin{tabular}{|c|c|c|}
\hline Test & AUC & S.E. \\
\hline Basal cortisol & 0.775 & 0.080 \\
\hline APST 60 & 0.956 & 0.027 \\
\hline APST 120 & 0.986 & 0.012 \\
\hline Peak cortisol after APST & 0.978 & 0.017 \\
\hline Mean of APST cortisol & 0.977 & 0.017 \\
\hline Delta cortisol with APST & 0.966 & 0.024 \\
\hline
\end{tabular}

(corresponding to an SST cut off of $18 \mu \mathrm{g} / \mathrm{dL}$ ). Thirty unit dose of Acton Prolongatum ${ }^{\circledR}$ was found to be as potent as Synacthen $250 \mu \mathrm{g}$ in stimulating cortisol secretion in normal as well as glucocorticoid-insufficient patients.

The values of ACTH stimulated cortisol are assay dependent. The proposed newer cut offs for SST while using assays with better sensitivity and analyte specificity (as in the present study) range from 12.7 to $14.5 \mu \mathrm{g} / \mathrm{dL}$ which would be more relevant in patients with secondary AI $(7,8,9)$. If a cut off value of $14.5 \mu \mathrm{g} / \mathrm{dL}$ on SST was used for the diagnosis of AI in this study, the corresponding value for APST would be $18.6 \mu \mathrm{g} / \mathrm{dL}$ based on ROC analysis.

In practice, clinical features and plasma ACTH are used to differentiate between primary and secondary AI. In the present study it was noted that patients with primary AI achieve a much lower mean peak cortisol level than those with secondary AI. Further studies may be required to validate APST for the differentiation of primary and secondary adrenal insufficiency as this may be helpful in a setting where plasma ACTH testing is not feasible.

Gundguruthy et al. studied the efficacy of porcine sequence corticotropin in healthy volunteers and those with AI albeit without a documented comparison to a gold standard test (ITT or SST) (6). The average cortisol level achieved in patients with normal adrenal reserve in our study on APST was $26.1 \pm 5.6 \mu \mathrm{g} / \mathrm{dL}$, whereas that in the control group of the aforementioned study was $29.6 \pm 5.9$ $\mu \mathrm{g} / \mathrm{dL}$. Another study by Wagmode et al. documented the response of both tests but, the study included healthy volunteers only (12). Sharma et al. have compared the long acting ACTH (Acton Prolongatum ${ }^{\circledR}$ ) test against ITT for the diagnosis of secondary $\mathrm{AI}$ in children in which the peak values of cortisol obtained on the ACTH test were much higher than those on the ITT (13). This effect was also observed with the SST in several previous studies and is probably related to the supra-physiological plasma levels of ACTH attained with $250 \mu \mathrm{g}$ of Synacthen which is same as in the case of using Acton-Prolongatum ${ }^{\circledR}$ (14). However, the present study, as well as that by Wagmode et al. have noted insignificant differences in the stimulated cortisol values with both Synacthen and Acton Prolongatum ${ }^{\circledR}$. The Porcine sequence corticotrophin has also been used to identify AI in critically ill patients and in patients with HIV infection from two different centers in India $(15,16)$. The findings of previous studies related to Acton Prolongatum ${ }^{\circledR}$ are summarized in Table 3.

Using Acton Prolongatum ${ }^{\circledR}$ for diagnosis of adrenal insufficiency brings down the cost of investigation

Table 3 Summary of previous studies on porcine ACTH.

\begin{tabular}{|c|c|c|}
\hline Reference & Study subjects & $\begin{array}{l}\text { Comparative } \\
\text { standard used }\end{array}$ \\
\hline (10) & 10 healthy volunteers & nil \\
\hline (11) & 15 female dogs & Synacthen $250 \mu \mathrm{g}$ \\
\hline (6) & $\begin{array}{l}24 \text { healthy controls; } 24 \\
\text { adrenal insufficient }\end{array}$ & nil \\
\hline
\end{tabular}

15 healthy volunteers Synacthen $250 \mu \mathrm{g}$

48 suspected patients; 28 sufficient, 20 insufficient children

\begin{tabular}{c}
$\begin{array}{c}\text { Dose of } \\
\text { porcine ACTH }\end{array}$ \\
\hline $40 \mathrm{IU}$ \\
$2.2 \mathrm{IU} / \mathrm{kg}$ \\
$25 \mathrm{IU}$ \\
$25 \mathrm{IU}$ \\
\\
$25 \mathrm{IU}$
\end{tabular}

Findings

11-hydroxyl corticosteroid peak between 1 to $3 \mathrm{~h}$

Similar maximal secretion from adrenocortical reserve by both agents

Statistically significant difference in Acton Prolongatum stimulated cortisol and delta cortisol in normal and adrenal insufficient groups

Comparable peak serum cortisol in tetracosactide and porcine sequence corticotropin group $(P=0.686)$

Peak cortisol value $<18 \mu \mathrm{g} / \mathrm{dL}$ on the IM-ACTH suggestive of Al; Serum cortisol value $>22 \mu \mathrm{g} / \mathrm{dL}$ ruled out secondary $\mathrm{Al}$ in children (5-14 years) 
considerably. Acton Prolongatum ${ }^{\circledR}$ when used at a dose of 30 units per test costs 14 times less than the $250 \mu \mathrm{g}$ of Synacthen and using APST in lieu of SST can bring down the total cost of diagnosing glucocorticoid deficiency from USD 44 to 11 (Indian Rupees 3100 to 800).

The strength of the present study is the comparison of APST with an existing standard of care (SST), in individuals with both glucocorticoid sufficiency as well as deficiency, being the first one to do so. Limitations of our study include absence of dose titration of porcine ACTH and lack of an assay specific cut-off for Synacthen-stimulated serum cortisol in our laboratory. As opposed to previous studies using 25 units of Acton Prolongatum ${ }^{\circledR}$ for the APST, this study used 30 units considering the ease of dispensing from a $5 \mathrm{~mL}$ vial containing 300 units $(6,12,13)$. No adverse events were observed with Synacthen or Acton Prolongatum in the present study. Anaphylactic reactions to either can occur, although rarely in the present era due to the improved methods of purification (17).

\section{Conclusion}

Acton Prolongatum ${ }^{\circledR}$ stimulation test (APST) can accurately diagnose glucocorticoid insufficiency. Use of this long-acting porcine sequence ACTH in conjunction with morning cortisol levels can bring down the cost of diagnosing glucocorticoid insufficiency considerably and make the test accessible and affordable to large parts of the world.

\section{Declaration of interest}

The authors declare that there is no conflict of interest that could be perceived as prejudicing the impartiality of this study.

\section{Funding}

This study was funded by the provincial government (State Board of Medical Research, Kerala) vide order no. A2 (SBMR.2017-2018)/15182/2017/MCT dated 10.7.2017 granted to $\operatorname{Dr} C$ Jayakumari.

\section{Acknowledgements}

The authors thank Dr Mathew John, Consultant Endocrinologist at Providence Endocrine Centre, Thiruvananthapuram for the logistic help provided for this study. Dr Nandini Prasad, Dr S Soumya and Dr T Ajeesh (Senior Residents), Dr T P Seena (Physiological Assistant), S Sajeev, Arya Suresh, Arya Sugesh and Sudi Sisupalan (Research Assistants) in Department of Endocrinology, Govt. Medical College, Thiruvananthapuram, are acknowledged for their role in data collection and tabulation. Dr A Arun Kumar, Assistant Professor, Depatment of Anaesthesiology, Government Medical College, Thiruvananthapuram is acknowledged for proof reading the manuscript. The authors are thankful to the State Board of Medical Research, Kerala for funding the study.

\section{References}

1 Stewart PM \& Newell-Price JDC. The adrenal cortex. In Williams Textbook of Endocrinology, 13th ed., pp 490-555. Eds S Melmed, KS Polonsky, PR Larsen \& HM Kronenberg. Philadelphia, PA: Elsevier, 2016.

2 Kazlauskaite R, Evans AT, Villabona CV, Abdu TA, Ambrosi B, Atkinson $\mathrm{AB}$, Choi CH, Clayton RN, Courtney CH, Gonc EN et al. Corticotropin tests for hypothalamic-pituitary-adrenal insufficiency: a metaanalysis. Journal of Clinical Endocrinology and Metabolism 2008 93 4245-4253. (https://doi.org/10.1210/jc.2008-0710)

3 Yo WS, Toh LM, Brown SJ, Howe WD, Henley DE \& Lim EM. How good is a morning cortisol in predicting an adequate response to intramuscular synacthen stimulation? Clinical Endocrinology 201481 19-24. (https://doi.org/10.1111/cen.12373)

4 Bornstein SR, Allolio B, Arlt W, Barthel A, Don-Wauchope A, Hammer GD, Husebye ES, Merke DP, Murad MH, Stratakis CA et al. Diagnosis and treatment of primary adrenal insufficiency: an Endocrine Society clinical practice guideline. Journal of Clinical Endocrinology and Metabolism 2016101 364-389. (https://doi. org/10.1210/jc.2015-1710)

5 Ospina NS, Al Nofal A, Bancos I, Javed A, Benkhadra K, Kapoor E, Lteif AN, Natt N \& Murad MH. ACTH stimulation tests for the diagnosis of adrenal insufficiency: systematic review and metaanalysis. Journal of Clinical Endocrinology and Metabolism 2016101 427-434. (https://doi.org/10.1210/jc.2015-1700)

6 Gundgurthi A, Garg MK, Dutta MK \& Pakhetra R. Intramuscular ACTH stimulation test for assessment of adrenal function. Journal of the Association of Physicians of India 201361 320-324.

7 Raverot V, Richet C, Morel Y, Raverot G \& Borson-Chazot A. Establishment of revised diagnostic cut-offs for adrenal laboratory investigation using the new Roche Diagnostics Elecsys $₫$ cortisol II assay (Letter to the Editor). Annales d'Endocrinologie 201677 620-622. (https://doi.org/10.1016/j.ando.2016.05.002)

8 Kline GA, Buse J \& Krause RD. Clinical implications for biochemical diagnostic thresholds of adrenal sufficiency using a highly specific cortisol immunoassay. Clinical Biochemistry 201750 475-480. (https://doi.org/10.1016/j.clinbiochem.2017.02.008)

9 El-Farhan N, Pickett A, Ducroq D, Bailey C, Mitchem K, Morgan N, Armston A, Jones L, Evans C \& Rees DA. Method-specific serum cortisol responses to the adrenocorticotrophin test: comparison of gas chromatography-mass spectrometry and five automated immunoassays. Clinical Endocrinology 201378 673-680. (https://doi. org/10.1111/cen.12039)

10 Feldman EC, Stabenfeldt GH, Farver TB \& Addiego LA. Comparison of aqueous porcine ACTH with synthetic ACTH in adrenal stimulation tests of the female dog. American Journal of Veterinary Research 198243 522-524.

11 Friedman M. Comparison of duration of activity of corticotrophingelatin and corticotrophin-carboxymethyl cellulose. BMJ 19673 409-410. (https://doi.org/10.1136/bmj.3.5562.409)

12 Wagmode N, Mathew V, Bantwal G, Ayyar V, George B, Patanjali CP $\&$ Michael J. It is time to carpe diem with porcine ACTH - a comparison of porcine sequence corticotropin to tetracosactide hexaacetate in testing the hypothalamic pituitary adrenal axis in healthy individuals. Indian Journal of Endocrinology and Metabolism 201822 636-640. (https://doi.org/10.4103/ijem.IJEM_114_18)

13 Sharma R, Madathil S, Maheshwari V, Roy K, Kumar B \& Jain V. Long-acting intramuscular ACTH stimulation test for the diagnosis of secondary adrenal insufficiency in children. Journal of Pediatric Endocrinology and Metabolism 201832 57-63. (https://doi. org/10.1515/jpem-2018-0330)

14 Reimondo G, Bovio S, Allasino B, Terzolo M \& Angeli A. Secondary hypoadrenalism. Pituitary 200811 147-154. (https://doi. org/10.1007/s11102-008-0108-4) 
15 Das SN, Sahu NC, Darjee DR, Mishra SK, Swaroop S, Suna SP, Salim SKM \& Thatoi PK. Glucocorticoid response to intramuscular ACTH stimulation in critically ill patients. Journal of Evolution of Medical and Dental Sciences 20174 13-32.

16 Sharma N, Sharma LK, Anand A, Gadpayle AK, Gaurav K, Mukherjee S, Kulshreshtha B \& Dutta D. Presence, patterns and predictors of hypocortisolism in patients with HIV infection in India. Indian Journal of Medical Research 2018147 142-150. (https://doi. org/10.4103/ijmr.IJMR_43_16)

17 Rosenblum AH \& Rosenblum P. Anaphylactic reactions to adrenocorticotrophic hormone in children. Journal of Pediatrics 1964 64 387-395. (https://doi.org/10.1016/s0022-3476(64)80191-8)

Received 18 July 2019

Revised version received 11 October 2019

Accepted 14 October 2019 